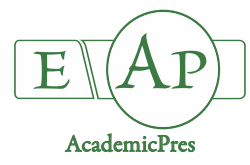

\title{
Effect of Different DNA Demethylating Agents on In vitro Cultures of Peach Rootstock GF 677
}

\author{
Miroslav BARÁNEK ${ }^{1 *}$, Miroslav OTMAR², Marcela KREČMEROVÁ2, \\ Aleš EICHMEIER ${ }^{1}$, Jana MOUDRÁ ${ }^{1}$, Zuzana MYNARZOVÁ ${ }^{1}$ \\ ${ }^{1}$ Mendel University in Brno, Faculty of Horticulture, Mendeleum - Institute of Genetics, Valtická 334, Lednice 69144, \\ Czech Republic; miroslav.baranek@mendelu.cz (*corresponding author); ales.eichmeier@mendelu.cz; jana.moudra@mendelu.cz; \\ zuzana.mynarzova@natic.cz \\ ${ }^{2}$ Institute of Organic Chemistry and Biochemistry, Academy of Sciences of the Czech Republic, v.v.i., Flemingovo nám. 2, CZ-166 10, Prague 6, \\ CzechRepublic; marcela.krecmerova@uochb.cas.cz;otmar@imc.cas.cz
}

\begin{abstract}
The appearance of somaclonal variability induced by in vitro cultivation is relatively frequent and, in some cases, provides a valuable source of new phenotypes suitable for crop improvement. Numerous studies have confirmed that these changes can be explained by alterations of DNA methylation. Interestingly, a group of chemical compounds termed 'demethylating agents' (DMT agents) enable artificial changes to be made in the DNA methylation state. Thus, these agents are theoretically able to induce new phenotypes or more favourable properties. The objective of the present study was to verify suitable conditions for the application of different DMT agents within in vitro protocols for micropropagation using the stone fruit rootstock GF 677 as an example. The impact of these agents on the properties of plant regenerants was evaluated, and their DNA methylation state was controlled by using an AFLP protocol based on a restriction endonuclease that differed in its sensitivity to methylated cytosines. Moreover, the effect of newly synthesised derivates was compared with that of conventional compounds with a well-documented DNA-demethylating impact. Based on the results, the suitable concentration for treatment by a DMT agent was established as approximately $50 \mu \mathrm{M}$. Promising results were generated using a combination of DMT agents with different mechanisms of action, such as azacytidine and dihydroxypropyladenine; under these conditions, probable synergy between methyltransferase interception by the cytosine analogue and interruption of methyl group donation by dihydroxypropyladenine significantly changed the DNA methylation state of treated plants. Regarding newly synthesised compounds, the 5,6-dihydro-5-azacytosine nucleoside showed the most promising results, which can likely be explained by its higher stability in the media used for in vitro cultivation.
\end{abstract}

Keywords: 5,6-dihydro-5-azacytosine; dihydroxypropyladenine; epigenetic changes; micropropagation; somaclonal variability

\section{Introduction}

Plant tissue culture can induce a number of deviations from the parental phenotype of grown plants, a phenomenon known as somaclonal variation (Larkin and Scowcroft, 1981). The occurrence of somaclonal variability is relatively frequent and, in some cases, provides a valuable source of genetic variation for crop improvement. For example, newly selected variants may exhibit resistance to biotic or abiotic factors that can lead to improved quality or higher yields (Karp, 1995; Mehta and Angra, 2000; Predieri, 2001; Unai et al., 2004); other valuable properties summarized by Smulders and de Klerk (2001) can also appear in regenerants. These changes can be caused by genetic mutation, but variation in the epigenome including
DNA methylation changes is frequently described as a reason for this variability (Popescu et al., 2002; Baránek et al., 2010; Sáez-Laguna, 2014; Baránek et al., 2015). A group of chemical compounds termed 'demethylating agents' (DMT agents) enable artificial hypomethylation of DNA in treated cells. This group includes some compounds with well-documented demethylating effects, such as 5azacytidine (AC), 5,6-dihydro-5-azacytidine (DHAC), zebularine, and (S)-9-(2,3-dihydroxypropyl)adenine (DHPA), as well as the recently identified demethylating agent alpha anomer of 5,6-dihydro-2'-deoxy-5-azacytidine (ALPHA DHDAC) (Matoušová et al., 2011; Krečmerová and Otmar, 2012). The application of these compounds can theoretically induce new phenotypes or more favourable properties in treated plants. 
It can also plausibly be assumed that the level of DNA methylation plays an important role in establishing some properties that are theoretically beneficial for enhancing the effectiveness of commercial in vitro propagation. Among some of the most important examples, reduced vitality of long-term re-used in vitro cultures is often observed. This decrease in vitality can be linked to increasing DNA methylation in these old cultures, while rejuvenated variants usually show decreased levels of DNA methylation (Valledor et al., 2007). Another advantageous effect is that rejuvenated plants exhibit greater root tissue differentiation (Smulders and de Klerk, 2011), which should theoretically improve the economics of in vitro regenerant rooting. Based on those premises, the application of DMT agents to in vitro-grown material can theoretically improve both of these factors associated with the effectiveness of in vitro propagation.

The most commonly used DMT compounds are cytidine analogues such as 5-azacytidine and zebularine. Once incorporated, the analogues covalently trap DNA methyltransferases and mediate their degradation, leading to passive loss of DNA methylation in the treated cells (Yoo et al., 2004; Stresemann and Lyko, 2008). Another compound with the power to influence DNA methylation levels is 9(2,3-dihydroxypropyl) adenine (DHPA), which effectively interferes with the degradation of the methyl-group donor competitor, S-adenosyl-L-homocysteine (SAH). DHPA blocks the hydrolysis of SAH and therefore prevents methyltransferases from carrying out further methylation (Schanche et al., 1984, Kovařík et al., 1994).

Long-term in vitro cultures of the GF 677 variety were used as study material in this work. The GF 677 variety is a hybrid of Prunus amygdalus $\times P$. persica and is commonly used as a rootstock for peach trees. There is a wellestablished protocol for the propagation of this particular rootstock by tissue culture, and there have been many studies involving the micropropagation of GF 677 (DimasiTheriou and Economou, 1995; Tsipouridis et al., 2005; Aghaye and Yadollahi, 2012).

The objectives of the present study were i) to determine a suitable range of concentrations for the tested group of DMT agents, ii) to evaluate the initial effect of the tested DMTs on the properties of micropropagated GF 677 rootstock plants from a morphological point of view and iii) to compare the ability of proven DNA-demethylating compounds and newly synthesised ones to change the DNA methylation state of in vitro cultures. To obtain the necessary data, AFLP fingerprints obtained by using the $M s p I$ endonuclease, which is sensitive to DNA methylation at recognized CCGG sequences, was used as a tool.

\section{Materials and Methods}

\section{Applied DMT agents}

Detailed information on the compounds used for treatment is listed in Table 1. Four DMT agents and one combination of agents that function on the basis of different demethylating principles (AC and DHPA) were added in the form of an aqueous solution to the initial growth media (details of the medium composition are provided in Chapter 2.2). Each compound was tested by using three different concentrations in the media: $10 \mu \mathrm{M}$, $50 \mu \mathrm{M}$ and $100 \mu \mathrm{M}$. For each DMT compound and its concentration, three replicates were performed in three glass containers.

\section{In vitro cultivation}

For the cultivation of GF 677 rootstock tissue cultures, glass containers with Quoirin and Lepoivre (1977) medium (pH 6.3) enriched with the different DMT compounds were prepared. Axillar shoot explants that were uniform in both their growth and physiological properties were transferred to the media, with each glass container holding five shoots, resulting in 15 individuals per treatment. These plants were maintained less than 16/8 hour of light/dark conditions in a $21^{\circ} \mathrm{C}$ growth chamber. The light intensity was $20.25 \mu \mathrm{mol} . \mathrm{m}^{-2} \cdot \mathrm{s}^{-1}$. After 10 days in this initial media, the plants were transferred to cytokinin-enriched $(1 \mathrm{mg}$ IBA) Quoirin and Lepoivre multiplication media (free of DMT compounds), subsequently maintained under these conditions for 20 days and subjected to morphological trait evaluation.

\section{Morphological evaluation}

The first assessment of the effect of the drugs on the cultures was performed after 10 days in the DMT compound-enriched Quoirin and Lepoivre media. Further morphological trait evaluations were performed after 7 and 20 days in the cytokinin-enriched Quoirin \& Lepoivre multiplication media (free of DMT agents). Each evaluation included photo-documentation, estimation of biomass by measuring shoot cluster size and examination of evident changes in behaviour or phenotype compared to the control (untreated) culture.

AFLP fingerprints obtained by using $M s p I$ as an endonuclease sensitive to DNA methylation

As a source for the isolation of DNA corresponding to each treatment variant, tissues were obtained from whole vitro plants, and three replicates were performed for each variant. The material was collected after 10 days in the basic Quoirin and Lepoivre media including the different DMT agents with set concentrations, resulting in a total of 18 samples including the untreated control variant. For the DHPA variants, only the samples treated with concentrations of $100 \mu \mathrm{M}$ and $50 \mu \mathrm{M}$ were included in the AFLP analysis due to slight bacterial infection of the $10 \mu \mathrm{M}$ variant, which did not pose problems concerning morphological trait evaluation but could ultimately affect the MSAP results. For DNA isolation, the DNeasy Plant Mini Kit (Qiagen) was used in accordance with the manufacturer's instructions.

A $300 \mathrm{ng}$ sample of isolated DNA was digested with the $M s p I / E c o R I$ enzyme combination. MspI can cleave nonmethylated CCGG sequences and hemi- $\left({ }^{\mathrm{m}} \mathrm{C}\right.$ only on one DNA strand) or fully methylated $\mathrm{C}^{\mathrm{m}} \mathrm{CGG}$ sequences but not hemi- and fully methylated ${ }^{\mathrm{m}} \mathrm{C} C \mathrm{CG}$ and ${ }^{\mathrm{m}} \mathrm{C}^{\mathrm{m}} \mathrm{CGG}$ sequences (Fulneček and Kovař́k, 2014); therefore, comparison of the obtained amplicon spectra among the analysed samples allows evaluation of the degree of the changes in their DNA methylation landscape. 
Table 1. List of the compounds used for the treatment

\begin{tabular}{|c|c|c|c|}
\hline Code of the compound & Structural formula & Molar mass (M) & Supplier \\
\hline 5-Azacytidine (AC) & & 244.21 & $\begin{array}{c}\text { Institute of Organic } \\
\text { Chemistry and Biochemistry }\end{array}$ \\
\hline $\begin{array}{c}\text { 5,6-Dihydro-5-azacytidine, acetate } \\
\text { salt (DHAC) }\end{array}$ & & 306.27 & $\begin{array}{c}\text { Institute of Organic } \\
\text { Chemistry and Biochemistry }\end{array}$ \\
\hline $\begin{array}{l}\text { Alpha anomer of 5,6-dihydro-2'- } \\
\text { deoxy-5-azacytidine, acetate salt } \\
\text { (ALPHA DHDAC) }\end{array}$ & & 290.28 & $\begin{array}{c}\text { Institute of Organic } \\
\text { Chemistry and Biochemistry }\end{array}$ \\
\hline Zebularine & & 228.20 & Sigma-Aldrich \\
\hline $\begin{array}{c}\text { (S)-9-(2,3-dihydroxypropyl)adenine } \\
\text { (DHPA) }\end{array}$ & & 209.09 & $\begin{array}{c}\text { Institute of Organic } \\
\text { Chemistry and Biochemistry }\end{array}$ \\
\hline
\end{tabular}

The restricted fragments were ligated with EcoRI/MspI adaptors. The conditions and adaptor sequences used as well as the following steps were carried out as in Baránek et al. (2010). The total number of primer combinations used was 6.

The distribution of amplicons within individual treatments was classified as present (1) or absent (0). The data were entered into a computer file as a binary matrix. The obtained binary matrix representing the presence or absence of individual amplicons was analysed using the Nei and $\mathrm{Li} / \mathrm{Dice}$ algorithm (Nei and $\mathrm{Li}, 1979$ ). Based on the coefficients of similarity calculated by the UPGMA method, a dendrogram was created using FreeTree software (Hampl et al., 2001).

\section{Results}

\section{Morphological evaluation}

The results of the assessment (Table 2) showed a retardation effect of some of the tested compounds, where 5-azacytidine (AC) exerted the strongest influence. Surprisingly, the combined $\mathrm{AC}+\mathrm{DHPA}$ treatment group was not hindered by significant growth inhibition, and the growth rate of the treated plants was comparable with that of the control and the DHPA-treated plants in the first term of evaluation. All observed deviations from the control occurred in a concentration-dependent manner, with higher concentrations making the variations more pronounced. In most cases, after the initial growth decline, the plants grown in the $10 \mu \mathrm{M}$ media exhibited similar growth intensity to the control plants 20 days after transfer to multiplication media. In the case of the $100 \mu \mathrm{M}$ concentration, the growth inhibition effect seemed to persist, and the plants showed a continuous decrease in biomass production throughout the entire morphological trait assessment period (i.e., for 30 days after the application of DMT agents). No notable changes in phenotype were detected during the evaluation period, except for larger or slightly curled leaves in the DHPA-treated variant, as indicated in Table 2.

Comparison of AFLP fingerprints obtained by using MspI as an endonuclease sensitive to DNA methylation

The total number of evaluated amplicons was 594. All treated plants showed significant differences in their DNA 
Table 2. Results of morphological evaluation

\begin{tabular}{|c|c|c|c|c|}
\hline \multirow[t]{2}{*}{ Used compound } & \multirow[t]{2}{*}{ Concentration } & $\begin{array}{c}\text { Biomass evaluation } \\
(\% \text { of control }) \text { - variant } A^{*}\end{array}$ & $\begin{array}{c}\text { Biomass evaluation } \\
(\% \text { of control }) \text { - variant } B^{* *}\end{array}$ & $\begin{array}{c}\text { Biomass evaluation } \\
(\% \text { of control }) \text { - variant } C^{* * *}\end{array}$ \\
\hline & & Other effect & Other effects & Other effects \\
\hline \multirow{2}{*}{$\mathrm{AC}$} & $10 \mu \mathrm{M}$ & 60 & 70 & 70 \\
\hline & $50 \mu \mathrm{M}$ & 50 & 60 & 50 \\
\hline \multirow{5}{*}{ DHAC } & $100 \mu \mathrm{M}$ & 50 & 50 & 40 \\
\hline & $10 \mu \mathrm{M}$ & 90 & 100 & 100 \\
\hline & $50 \mu \mathrm{M}$ & 80 & 80 & 80 \\
\hline & $100 \mu \mathrm{M}$ & 70 & 70 & 60 \\
\hline & $10 \mu \mathrm{M}$ & 80 & 90 & 100 \\
\hline \multirow[t]{4}{*}{ ALPHA DHDAC } & $50 \mu \mathrm{M}$ & 80 & 80 & 70 \\
\hline & $100 \mu \mathrm{M}$ & 70 & 60 & 50 \\
\hline & & & 90 & 70 \\
\hline & $10 \mu \mathrm{M}$ & 90 & Bigger leaves & Less shoots, bigger leaves \\
\hline \multirow[t]{4}{*}{ DHPA } & & & 90 & 80 \\
\hline & $50 \mu \mathrm{M}$ & 80 & Bigger leaves & Less shoots, bigger leaves \\
\hline & 100,4 & 100 & 100 & 90 \\
\hline & $100 \mu \mathrm{M}$ & Bigger leaves & Curled leaves & Curled leaves \\
\hline \multirow{3}{*}{ Zebularine } & $10 \mu \mathrm{M}$ & 80 & 80 & 90 \\
\hline & $50 \mu \mathrm{M}$ & 60 & 60 & 60 \\
\hline & $100 \mu \mathrm{M}$ & 50 & 50 & 40 \\
\hline \multirow{4}{*}{$\mathrm{AC}+\mathrm{DHPA}$} & $10 \mu \mathrm{M}$ & 90 & 100 & 100 \\
\hline & \multirow[t]{2}{*}{$50 \mu \mathrm{M}$} & \multirow[t]{2}{*}{90} & \multirow[t]{2}{*}{80} & 70 \\
\hline & & & & Less shoots \\
\hline & $100 \mu \mathrm{M}$ & 90 & 80 & $\begin{array}{c}60 \\
\text { Smaller growth }\end{array}$ \\
\hline Control & - & 100 & 100 & 100 \\
\hline
\end{tabular}

* biomass of the plants after 10 days on media with respective DNA demethylating compound

** biomass of the plants 7 days after the transfer from media with respective demethylating compound on multiplication media

${ }^{* * *}$ biomass of the plants 20 days after the transfer from media with respective demethylating compound on multiplication media

methylation landscape in comparison with the control, whereas the average coefficient of MSAP spectrum similarity between all variants was computed as 0.6124 . Regarding the strength of the ability of individual compounds to change the DNA methylation landscape, the lowest coefficients of similarity on average were obtained for variants derived from DHAC treatment compared with the untreated control. In fact, the average similarity under the 10,50 and $100 \mu \mathrm{M} \mathrm{DHAC}$ concentrations was 0.5654 .

The dendrogram constructed on the basis of mutual similarity coefficients (Fig. 1) showed that the variants could be categorized into three distinct groups. The group showing highest similarity with the control variants was mainly composed of AC-treated variants from all three tested concentrations and two variants obtained under zebularine treatment.

Another branch of the dendrogram comprised the ALPHA DHDAC-treated samples from the whole concentration spectrum and the $100 \mu \mathrm{M}$ DHPA-treated samples, indicating the pronounced effect of the DMT agent concentration. The last group, located in the upper part of the dendrogram, included variants showing the greatest distinctness of their methylation status compared to the control. It was not surprising that variants obtained under the DMT agent combination of AC+DHPA were also included in this cluster, confirming their theoretical synergic effect on the hypomethylated genome of the treated tissues. Interestingly, the samples treated by all concentrations of DHAC were also included in this cluster, indicating that this compound is highly promising for in vitro applications in experiments focused on decreasing DNA methylation status in treated tissue.

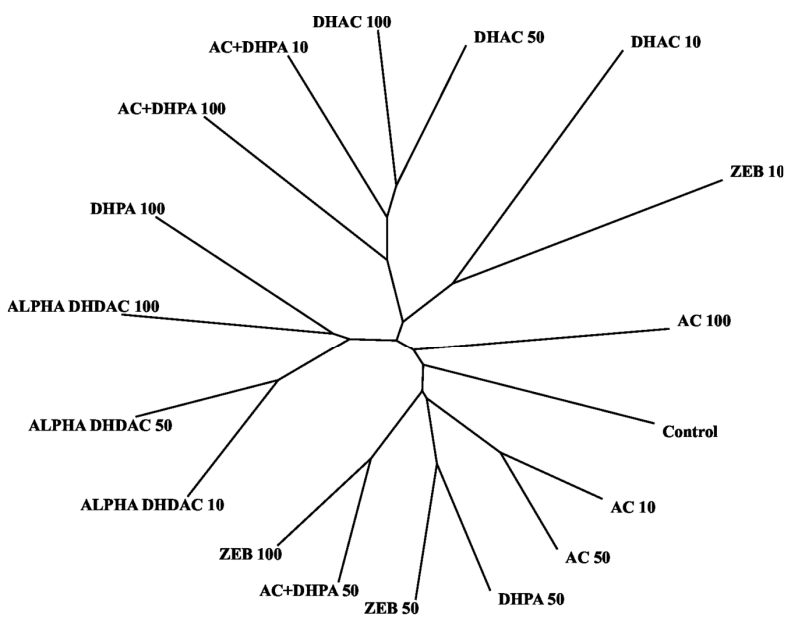

Fig. 1. Dendrogram showing the similarity of AFLP spectra generated by using the methylation-sensitive MspI endonuclease 
900

\section{Discussion}

The main purposes of this work were to verify conditions suitable for the application of DMT agents and their effect on in vitro cultures as potential inducers of beneficial changes and to compare some traditional and newly designed DNA-demethylating compounds. The results of the morphological analysis showed a significant number of changes compared to the untreated control. The most frequent of these changes was growth retardation, which was most prominent when using AC. However, the results of AFLP analysis of the modulation of the DNA methylation landscape grouped the plants treated with $\mathrm{AC}$ with the control variant (Fig. 1), indicating that the differences in growth rates may not have been due to the demethylating effect of the drug. This finding was not surprising in light of the information that in addition to the ability to be incorporated into DNA and inhibit its methylation, AC is also incorporated into RNA and inhibits protein synthesis (Fučík et al., 1970; Diesch et al., 2016) while decreasing the stability of polyribosomes and the maturation of rRNA (Reuveni and Rosenthal, 1979). Furthermore, AC has been indicated to be quite unstable in aqueous solutions and is sensitive to light and oxidation (Notari and DeYoung, 1975; Diesch et al., 2016). The delay of growth and other differences observed in comparison with the control may therefore have been caused by other mechanisms of change that are independent of DNA methylation status and are therefore not measurable by MSAP analysis.

On the other hand, although zebularine exhibits a much longer half-life under physiological conditions and fewer side effects than AC (Cheng et al., 2003), zebularine can induce DNA damage during strand synthesis in DNA replication, triggering a DNA damage response independent of changes in DNA methylation status (Liu et al., 2015). The grouping of variants treated by zebularine within the generated dendrogram (Figure 1) indicated that zebularine had a relatively small effect on DNA methylation. However, zebularine was previously proven to induce a significant decrease in cytosine methylation (Baubec et al., 2009), which is seemingly in direct opposition to the results obtained in the present study. One possible explanation for this disparity could be the different experimental backgrounds between the compared experiments. Within the present study, compounds with stronger demethylating effects were used, making zebularine substandard within this experiment, although it was still strong enough to be described as very effective, as indicated by Baubec et al. (2009).

In the case of the sub-cluster including the variants that deviated most from the control (upper part of Fig. 1), the combined effect of AC+DHPA seemed to introduce the most prominent changes in the DNA methylation patterns of the treated plants, together with DHAC. The enhanced effect of DHAC can be explained by the better physical properties of this compound, such as its better solubility in aqueous solutions or better stability in agar media. In fact, DHAC and ALPHA DHDAC differ from the classic 5azacytidine nucleosides in the saturation of the double bond at position 5,6 in their structure. This difference results in significant improvement of their stability as well as an increase in their basicity. Therefore, these compounds are prepared as salts with acids (as a salt of acetic acid in this case). Interestingly, the second substance with the 5,6dihydro modification, ALPHA DHDAC, also showed promising results in terms of its demethylating effect. As can be seen from the dendrogram, treatment with both 5,6dihydro-5-azacytosine compounds exerted a stronger effect than treatment with commonly used DMT agents, such as zebularine or AC. Based on this finding, 5,6-dihydro-5azacytosine compounds can be recommended for use in experiments focused on decreasing the DNA methylation state in plant tissues maintained under in vitro conditions. However, the realization of this strategy can be difficult due to the limited availability of this compound. Another possibility for inducing a relatively strong DNAdemethylating effect is to use the combination of $\mathrm{AC}+\mathrm{DHPA}$, as shown by the presented results.

The obtained results may also be generally important in other scientific arenas where the use of effective DNAdemethylating agents is highly desirable, such as environmental studies focused on the transgenerational effects of plant adaptation to stresses, in which DNA methylation probably plays a role (Latzel et al. 2016; Gonzáles et al., 2017), and studies focused on the phenomenon of plant inbreeding depression (Vergeer and Wagamaker, 2012), gene expression (Bossdorf et al., 2010; Kiselev et al., 2011) or the rate of point mutations (Kiselev, 2019).

\section{Conclusions}

The obtained results indicate the importance of the concentration of DMT compounds, as the morphological and growth rate differences increases with the dosage if compared with the untreated control. Based on the presented results, the optimal concentration for DMT agent treatment is approximately $50 \mu \mathrm{M}$, where the effect on methylation levels is clear, but no significant retardation of growth is observed. Promising results from the perspective of the DNA-demethylating effect were generated using a combination of DMT agents with different mechanisms of action, such as azacytidine and dihydroxypropyladenine (DHPA), where probable synergy between methyltransferase interception by the cytosine analogue and interruption of methyl group donation by DHPA changed the DNA methylation state of the treated plants. Regarding newly synthesised compounds, the 5,6dihydro-5-azacytosine (DHAC) nucleoside showed the most promising results, which can likely be explained by its higher stability in the media used for in vitro cultivation.

\section{Acknowledgements}

This work was supported by the project LTC18009, program INTER-COST provided by the Ministry of Education, Youth and Sports of the Czech Republic. The study was also supported from EFRR "Multidisciplinary research to increase application potential of nanomaterials in agricultural practice" (No. CZ. 02. 1. 01 /0.0 /0.0/ 16 025/0007314). 


\section{Conflicts of interest}

The authors declare that there are no conflicts of interest related to this article.

\section{References}

Aghaye RNM, Yadollahi A (2012). Micropropagation of GF 677 rootstock. Journal of Agricultural Science 4(5):1916-9752.

Baránek M, Křižan B, Ondrušíková E, Pidra M (2010). DNA-methylation changes in grapevine somaclones following in vitro culture and thermotherapy. Plant Cell, Tissue and Organ Culture 101(1):11-22.

Baránek M, Čechová J, Raddová J, Holleinová V, Ondrušiková E, Pidra M (2015). Dynamics and reversibility of the DNA methylation landscape of grapevine plants (Vitis vinifera) stressed by in vitro cultivation and thermotherapy. PloSOne 10:e0126638.

Baubec T, Pecinka A, Rozhon W, Mittelsten Scheid O (2009). Effective, homogeneous and transient interference with cytosine methylation in plant genomic DNA byzebularine. Plant Journal 57(3):542-554.

Bossdorf O, Arcuri D, Richards CL, Pigliucci M (2010). Experimental alteration of DNA methylation affects the phenotypic plasticity of ecologically relevant traits in Arabidopsis thaliana. Evolutionary Ecology 24(3):541-553.

ChengJC, Matsen CB, Gonzales FA, Ye W, Greer S, Marquez F, ... Selker EU (2003). Inhibition of DNA methylation and reactivation of silenced genes by zebularine. Journal of the National Cancer Institute 95(5):399-409.

Diesch J, Zwick A, Garz AK, Palau A, Buschbeck M, Götze KS (2016). A clinical-molecular update on azanucleoside-based therapy for the treatment of hematologic cancers. Clinical Epigenetics 8(1):71.

Dimasi-Theriou K, Economou AS (1995). Ethylene enhances shoot formation in cultures of the peach rootstock GF-677 (Prunuspersica $\mathrm{x} P$. amygdalus). Plant Cell Reports 15(1-2):87-90.

Fučík V, Michaelis A, Rigomar R (1970). On the induction of segment extension and chromatid structural changes in Vicia faba chromosomes after treatment with 5-azacytidine and 5-azadeoxycytidine. Mutation Research/Fundamental and Molecular Mechanisms of Mutagenesis 9(6):599-606.

Fulneček J, Kovařík A (2014). How to interpret Methylation Sensitive Amplified Polymorphism(MSAP) profiles? BMC Genetics 15:2.

Fraga HP, Vieira LN, Caprestano CA, Steinmacher DA, Micke GA, Spudeit DA, ... Guerra MP (2012). 5-Azacytidine combined with 2, 4 D improves somatic embryogenesis of Acca sellowiana (O. Berg) Burret by means of changes in global DNA methylation levels. Plant Cell Reports 31(12):2165-2176.

González APR, Dumalasová V, Rosenthal J, Skuhrovec J, Latzel V (2017). The role of transgenerational effects in adaptation of clonal offspring of white clover (Trifolium repens) to drought and herbivory. Evolutionary Ecology 31(3):345-361.

Hampl V, Pavlícek A, Flegr J (2001). Construction and bootstrap analysis of DNA fingerprinting-based phylogenetic trees with a freeware program FreeTree: Application to trichomonad parasites. International Journal of Systematic and Evolutionary Microbiology 51(3):731-735.

Karp A (1995). Somaclonal variation as a tool for crop improvement. Euphytica 85(1-3):295-302.
KiselevKV, Tyunin AP, Manyakhin AY,Zhuravlev YN (2011). Resveratrol content and expression patterns of stilbene synthase genes in Vitis amurensis cells treated with 5-azacytidine. Plant Cell, Tissue and Organ Culture 105(1):65-72.

Kiselev KV, Ogneva ZV, Dubrovina AS, Nityagovsky NN, Suprun AR (2019). Somatic mutations, DNA methylation, and expression of DNA repair genes in Arabidopsis thaliana treated with 5-azacytidine. Biologia Plantarum 63:398-404.

Kovařik A, Koukalová B, Holý A, Bezděk M (1994). Sequence-specifc hypomethylation of the tobacco genome induced with dihydroxypropyladenine, ethionine and 5-azacytidine. FEBS Letters 353(3):309-311.

Krečmerová M, Otmar M (2012). 5-azacytosine compounds in medicinal chemistry: current stage and future perspectives. Future Medicinal Chemistry4(8):991-1005.

Latzel V, Rendina González AP, Rosenthal J (2016). Epigenetic memory asa basis for intelligent behavior in clonal plants. Frontiers in Plant Science 7:1354.

Liu CH, Finke A, Díaz M, Rozhon W, Poppenberger B,... Pecinka A (2015). Repair of DNA damage induced by the cytidine analog zebularine requires ATR and ATM in Arabidopsis. The Plant Cell 27(6):1788-1800.

Matoušová M, Votruba I, Otmar M, Tlouštová E, GünterováJ, MertlíkováKaiserová H (2011). 2'-deoxy-5,6-dihydro-5-azacytidine-a less toxic alternative of 2 '-deoxy-5-azacytidine A comparative study of hypomethylating potential. Epigenetics 6(6):769-776.

Mehta YR, Angra DC (2000). Somaclonal variation for disease resistance in wheat and production of dihaploids through wheat 9 maize hybrids. Genetics and Molecular Biology 23(3):617-622.

Nei M, Li WH (1979). Mathematical model for studying genetic variation in terms of restriction endonucleases. Proceedings of the National Academy of Sciences USA.76(10):5269-5273.

Notari RE, DeYoungJL (1975). Kinetics and mechanisms of degradation of the antileukemic agent 5-azacytidine in aqueous solutions. Journal of Pharmaceutical Sciences64(7):1148-57.

Popescu CF, Falk A, Glimelius K (2002). Application of AFLPs to characterize somaclonal variation in anther-derived grapevines. Vitis 41(4):177-182

Predieri S. (2001) Mutation induction and tissue culture in improving fruits. Plant Cell, Tissue and Organ Culture 64(2-3):185-210.

Quoirin M, Lepoivre P (1977). Improved media for in vitro culture of Prunussp. Acta Horticulturae(ISHS) 78:437-442.

Reuveni Y, Rosenthal LJ (1979). Effect of 5-azacytidine on cytoplasmic ribosomal and messenger ribonucleic acids in BSC-1 cells. Antimicrobial agents and chemotherapy 15(2):235-239.

Sáez-Laguna E, Guevara MA, Díaz LM, Sánchez-Gómez D, Collada C, ... Cervera MT (2014). Epigenetic variability in the genetically uniform forest tree species Pinuspinea L. PloS One 9(8): e103145.

SchancheJS, Schanche T, Ueland PM, Holý A, Votruba I(1984). The effect of aliphatic adenine analogues on S-adenosylhomocysteine and Sadenosylhomocysteine hydrolase in intact rat hepatocytes. Molecular Pharmacology 26(3):553-558.

Smulders MJM, De Klerk GJ (2011). Epigenetics in plant tissue culture. Plant Growth Regulation 63(2):137-146. 
902

Stresemann C, Lyko F (2008). Modes of action of the DNA methyltransferase inhibitors azacytidine and decitabine. International Journal ofCancer 123(1):8-13.

Tsipouridis C, Thomidis T, Michailides Z (2005). Factors influencing the rooting of peach GF677 (peach ¥ almond hybrid) hardwood cuttings in a growth chamber. New Zealand Journal of Crop and Horticultural Science 33(2):93-98.

Unai E, IselenT, de Garcia E (2004). Comparison of characteristics of bananas (Musa sp.) from the somaclone CIENBTA-03 and its parental clone Williams. Fruits 59(4):257-263.
Valledor L, Hasbún R, Meijón M, Rodríguez JL, Santamaría E, Viejo M, ... Rodríguez R (2007). Involvement of DNA methylation in tree development and micropropagation. Plant Cell, Tissue and Organ Culture 91(2):75-86.

Vergeer P, Ouborg NJ (2012). Evidence for an epigenetic role in inbreeding depression. BiologyLetters 8(5):798-801.

Yoo CB, ChengJC, Jones PA (2004). Zebularine: a new drug for epigenetic therapy. Biochemical Society Transactions 32:910-912. 